\title{
Editorial: Highway design and maintenance, road safety and traffic management
}

Aoife Foley BE, MSc, PhD, FHEA, CEng, FIEI

Reader and Advisor of Studies, School of Mechanical \& Aerospace

Engineering, Queen's University Belfast, Belfast, UK (a.foley@qub.ac.uk)

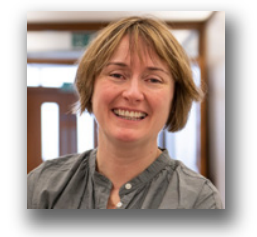

This is now my second editorial for the Proceedings of the Institution of Civil Engineers - Transport and once again I would like to express my immense honour in getting the opportunity to share this transport research from my colleagues around the world. This issue is well-timed considering societal expectations for safer and greener transport infrastructure and focuses on highway design and maintenance, road safety and traffic management (Quin, 2019). Balancing these societal expectations with increased road usage, reduced construction and operations and maintenance budgets as well as extreme weather events will be challenging. Globally, highway and road design is becoming greener, safer and smarter through the use of technology (IRU, 2019) and better environmental (Osterhues, 2006) and design standards (Highways England, 2019). However, research, such as that presented in this issue, is critical to inform and influence the field to provide even better guidance for designers and operators in meeting these societal expectations. This issue contains five articles that examine different aspects of design, safety and planning.

In the paper by $\mathrm{Xu}$ et al. (2019), the longitudinal acceleration of vehicles on complex mountain roads is examined in order to describe a vehicle's kinematic behaviour and driver behaviour patterns. Most studies to date have centred on urban environments. The results of this work demonstrated that $(a)$ even though the preferred acceleration rate does not vary much from driver to driver, preferred deceleration rate varies significantly; (b) the inflection points of the acceleration and deceleration cumulative frequency curves appear near the 91st percentile rather than the 85 th percentile currently used; $(c)$ as the radius of a curve increases, the acceleration and deceleration rates decrease; and $(d)$ that there is no significant correlation between the deceleration and the initial speed. These are important findings for design of roads and highways in mountainous terrain. In the paper by Pérez-Acebo et al. (2019), a deterioration model for predicting the available skid resistance on asphalt concrete roads in Biscay, Spain with no maintenance or rehabilitation by means of factors that have an influence on it is developed. The purpose of the model is to support operations and maintenance decision-making for the Road Agency in the region to anticipate friction conditions. The model formulated in the work corroborates Hosking and Woodford's Transport Research Laboratory (TRL) findings on pavement age considering the mean summer sideways force coefficient routine investigation machine (Scrim) coefficient (MSSC) (Hosking and Woodford, 1976) and certifies the findings of Rezaei and Masad (2013) and Kassem et al. (2013) on polishing cycles, meaning that for pavements older than 2 years old, age is not an influencing factor. The model developed by Pérez-Acebo et al. (2019) also showed that (a) bituminous layers do not influence the skid resistance, $(b)$ the mixing gradation (porous, discontinuous and semi-dense) is also not of great importance and $(c)$ the pavement structure type, flexible or semi-rigid, does not show much variation. The results of the model indicated that the heavy annual average daily traffic (H.AADT) and the required polished stone value (PSV) for the surface loading are the only factors that significantly influence the MSSC, when it reaches its minimum value. In addition, the annual average daily traffic (AADT) and the age, total thickness of bituminous layers and pavement structure and mixing type can be discarded in the prediction analysis. The work ultimately demonstrated for the Road Agency in the Basque region that the only aspect of the design and maintenance that it can influence to maintain a skid resistance value is the minimum PSV of the aggregates deployed in the surface layer. This work is useful for the field as it shows that modelling can be done by researchers in academia for local regions to meet their needs considering their specific concerns. With increased car ownership, pressure on land use and safety requirements, highway geometric design is becoming even more challenging; in the paper by Bassan (2019) design policies, model developments and the implementation of sight distances (SDs) on the interurban highway network in Israel considering the new Israeli geometric design policy and controls for rural (interurban) highways was reviewed. The study found that, compared to design policy in the United States of America, the Israeli design policy resulted in slightly lower design values for stopping sight distance (SSD), decision sight 
distance (DSD) and passing sight distance (PSD), but higher constrained passing sight distance (CPSD) design values. The key finding was that using DSD rather than SSD results in larger vertical radii and more restricted horizontal sightline offsets, which would directly affect construction costs and landscaping while maintaining driving safety.

In reinforcement learning considering traffic movement, the trade-off is between exploration of the traffic environment and exploitation of the knowledge already obtained; in the paper by Aslani et al. (2019), this is particularly important when managing congestion to mitigate environmental impacts (e.g., noise and emissions) and reduce transport costs (e.g., fuel and lost time). This analysis, unlike previous similar work (Sledge and Principe, 2017; van Otterlo and Wiering, 2012), aims to simulate traffic and drivers' behaviour more realistically. The adaptive traffic signal controller (ATSC)-based actor-critic (ATSC-AC) model presented in this work has the advantages of both actor-only and critic-only methods. The results importantly indicate that, over time, this method exploits more optimum green times, meaning that the ATSCAC out-performs a fixed-time controller. Such findings are relevant to those who are managing traffic in urban areas and facing congestion problems. In the paper by Haghani et al. (2019), two new methods for classifying crashes on road segments were developed. In the first method, an exposure index was used and in the second method, a crash prediction model (CPM) from the Highway Safety Manual (HSM) (NRC, 2010) was implemented. The two methods were then compared and it was determined that the CPM obtained the best results. Such research is useful to road designers and those tasked with ensuring safety.

In summary, the papers contained in this issue are important for practitioners working in highway design, operations and maintenance, road safety and traffic management to ensure safer and greener transport infrastructure. I hope that you find these papers in this issue of the Proceedings of the Institution of Civil Engineers - Transport informative and useful. Please feel free to email me any comments on this issue.

\section{REFERENCES}

Aslani M, Mesgari MS, Seipel S and Wiering M (2019) Developing adaptive traffic signal control by actor-critic and direct exploration methods. Proceedings of the Institution of Civil Engineers Transport 172(5): 289-298, https://doi.org/10.1680/jtran.17.00085.
Bassan S (2019) Review and design policy of sight distance types for the interurban highway system. Proceedings of the Institution of Civil Engineers - Transport 172(5): 274-288, https://doi.org/10.1680/ jtran.17.00075.

Haghani M, Jalalkamali R and Berangi M (2019) Assigning crashes to road segments in developing countries. Proceedings of the Institution of Civil Engineers - Transport 172(5): 299-307, https://doi.org/10.1680/jtran.17.00099.

Highways England (2019) Keep Us All moving. How You Can Help to Have a Safer, Smoother Journey. Highways England, Birmingham, UK. See https://highwaysengland.co.uk/motorways/ (accessed 27/08/2019).

Hosking JR and Woodford GC (1976) Measurement of Skidding Resistance: Part I. Guide to the Use of SCRIM. Transport and Road Research Laboratory, Crowthorne, UK, Report LR 737.

IRU (International Road Transport Union) (2019) Technology and Automation Will Define the Future of Road Transport. IRU, Geneva, Switzerland. See https://www.iru.org/resources/newsroom/ technology-and-automation-will-define-future-road-transport (accessed 27/08/2019).

Kassem E, Awed A, Masad E and Little DN (2013) Development of predictive model for skid loss of asphalt pavements. Transportation Research Record 2372: 83-96.

NRC (National Research Council) (2010) Highway Safety Manual (vol. 1). Aashto and Transportation Research Board, Washington, DC, USA.

Osterhues M (2006) On the way to greener highways. Public Roads 70(6): article 7. See https://www.fhwa.dot.gov/publications/ publicroads/06nov/07.cfm (accessed 27/08/2019).

Pérez-Acebo H, Gonzalo-Orden H and Rojí E (2019) Skid resistance prediction for new two-lane roads. Proceedings of the Institution of Civil Engineers - Transport 172(5): 264-273, https://doi.org/ 10.1680/jtran.17.00045.

Quin B (2019) AA sounds safety warning over smart motorways. The Guardian, 8 April. See https://www.theguardian.com/uk-news/ 2019/apr/08/aa-safety-warning-smart-motorways-hard-shoulder (accessed 27/08/2019).

Rezaei A and Masad E (2013) Experimental-based model for predicting the skid resistance of asphalt pavements. International Journal of Pavement Engineering 14(1): 24-35.

Sledge IJ and Príncipe JC (2017) Balancing exploration and exploitation in reinforcement learning using a value of information criterion. In 2017 IEEE International Conference on Acoustics, Speech, and Signal Processing. Institute of Electrical and Electronics Engineers, Piscataway, NJ, USA, pp. 2816-2820.

van Otterlo M and Wiering M (2012) Reinforcement learning and Markov decision processes. In Reinforcement Learning: State-of-the-Art (Wiering M and van Otterlo M (eds)). Springer, Berlin/Heidelberg, Germany, pp. 3-42.

Xu J, Yang K, Zhou J, Wang X and Shao YM (2019) Longitudinal acceleration of vehicles on complex mountain roads. Proceedings of the Institution of Civil Engineers - Transport 172(5): 249-263, https://doi.org/10.1680/jtran.16.00032. 